\title{
In safe hands?
}

National and international guidelines exist for the treatment of most diseases, but these are not infrequently based on studies from which older people are excluded due solely to the age criterion, or because of functional impairment and extensive comorbidity (1). However, it is precisely such patients who are subject to widespread use of pharmacotherapy. Assessment of benefits and indication are therefore a considerable challenge in the treatment of specific diseases in the elderly generally, and in the frail with multiple comorbidities in particular (2). Overtreatment of the elderly has traditionally attracted most attention (3), but caution should also be exercised with regard to undertreatment (4). This may be attributed to lack of knowledge, and at other times to underprioritisation due to discrimination and judgemental attitudes to the elderly (ageism) (5). As a tool in everyday clinical practice to avoid unwanted adverse effects and obtain better control when «sailing in unknown waters», we have access to userfriendly interactive databases such as DRUID (6) and other relevant guidelines (7). Pharmacotherapy in the elderly nevertheless requires a considerable degree of watchfulness above and beyond this.

In this issue of the Journal of the Norwegian Medical Association, Shafique and colleagues present a case study which is interesting from several angles (8). It concerns a woman well into her nineties who is admitted for acute peritonitis due to a perforated intestine. The cause is a foreign body in the form of a tablet in a «cut out» and sharply cornered aluminium foil piece from a blister pack. The incident ended with a successful surgical intervention, and the authors write that the patient was able to be discharged in a healthy condition.

The patient had many chronic diseases, was taking several drugs and was in a weakened state as a result of a recent acute illness. She also had reduced vision. Overall she may generally be defined as a geriatric patient. When admitted she was described as alert and aware. The case history does not describe her functional capacity in any greater detail, but the incident in question perhaps illustrates that she also had some cognitive impairment. She had moreover just been hospitalised and had received additional drugs which were to be taken as needed. No information is given as to whether she had a district nurse or other form of assistance in connection with her medication, or whether she used multiple dosing or manually dispensed medicines.

The patient safety campaign In safe hands should be familiar to the Journal's readers, and drugs have been a focus area, for example through the harmonisation of pharmaceutical lists and the emphasis on correct use of pharmaceuticals in nursing homes and in the home care service (9). These measures have been important at a systemic level. However, clinical practice is primarily concerned with individual patients, and it is a precondition that our recommendations are communicated to and discussed with the patient him/herself, and not infrequently with next of kin. In this area, all of us have doubtless committed sins of omission, whether or not we acknowledge these. Notwithstanding this, it is easy to foresee that an avalanche of information, particularly with regard to any uncertainty, can ruin an otherwise excellent consultation. This is a challenging practice.

If we find that the benefits outweigh the risk of adverse effects by a good margin, and if it is our opinion that precisely for you we would recommend this treatment, several steps remain. We have to ensure that the patient in fact has the drugs available and that they are taken in the right manner and at the right time. When prescribing, we naturally have to assess the patient's functional capacity. Does the patient or her next of kin have a sufficient understan- ding of how the medicines should be taken? Can the regimen be implemented in practice? If there is a deficiency in any of these areas, we must seek an alternative way of ensuring that the patient actually takes the drugs we consider it important that she should take. This can be overcome by using manually dispensed medicines or simply practical assistance in the situation where the patient is to take her medicines. However, on a normal busy day sufficient consideration is not always given to the fact that the patient has chronic functional impairment in areas such as sight, hearing, cognition and fine motor skills. Opening a blister pack can be difficult enough! Multiple dosing regimens are also unsuitable for emergency treatment or rapid changes in medication.

The responsibility for initiation and follow-up of treatment must be clearly defined. If the hospital doctor believes that a patient needs a new treatment, it must be ensured that the patient is actually capable of getting to the pharmacy for her medicines and that she will manage to take them correctly, or alternatively that there is someone who can assist her. It is not good enough to send the patient away with a prescription and discharge summary for her GP without having ascertained that the patient is capable of carrying through the treatment. The treatment follow-up is naturally most often the task of the GP. If the initiation of treatment must be left to others, this must then be communicated explicitly and in an acceptable way. It is to be hoped that we can thus avoid situations such as that described in the case study.

Although the case study also describes the benefits of modern imaging diagnostics and successful surgical treatment of an elderly patient with multiple comorbidities, the main lesson is connected to the challenges of pharmacotherapy in geriatric patients.

\section{Olav Sletvold}

olav.sletvold@ntnu.no

Olav Sletvold (born 1949) is a specialist in internal medicine and geriatrics, head of the Department of Geriatric Medicine, St. Olavs Hospital, and adjunct professor at the Department of Neuroscience, Norwegian University of Science and Technology.

The author has completed the ICMJE form and declares no conflicts of interest.

\section{References}

1. Crome P, Lally F, Cherubini A et al. Exclusion of older people from clinical trials: professional views from nine European countries participating in the PREDICT study. Drugs Aging 2011; 28: 667-77.

2. Smith SM, Soubhi H, Fortin M et al. Managing patients with multimorbidity: - systematic review of interventions in primary care and community settings. BMJ 2012; 345: e5205.

3. Hamilton H, Gallagher P, Ryan $\mathrm{C}$ et al. Potentially inappropriate medications defined by STOPP criteria and the risk of adverse drug events in older hospitalized patients. Arch Intern Med 2011; 171: 1013-9.

4. Gallagher PF, O'Connor MN, O'Mahony D. Prevention of potentially inappropriate prescribing for elderly patients: a randomized controlled trial using STOPP/START criteria. Clin Pharmacol Ther 2011: 89: 845-54.

5. Cherubini A, Corsonello A, Lattanzio F. Underprescription of beneficial medicines in older people: causes, consequences and prevention. Drugs Aging 2012; 29: $463-75$.

6. Legemiddelsiden. DRUID. www.legemiddelsiden.no/default.aspx?PagelD=768 (17.11.2014).

7. Rognstad S, Brekke M, Fetveit A et al. The Norwegian General Practice (NORGEP) criteria for assessing potentially inappropriate prescriptions to elderly patients. A modified Delphi study. Scand J Prim Health Care 2009: 27: 153-9.

8. Shafique MR, Rekkedal LM, Berg M et al. En kvinne i 90-årene med akutt peritonitt. Tidsskr Nor Legeforen 2014; 134: 2280-2.

9. I trygge hender. www. pasientsikkerhetsprogrammet.no/ (17.11.2014). 